\title{
PENGEMBANGAN PERKEBUNAN KARET DALAM USAHA PENINGKATAN EKONOMI DAERAH DAN PENDAPATAN PETANI DI PROVINSI ACEH
}

\author{
Kasman \\ Perguruan Tinggi Alwashliyah Banda Aceh \\ E-mail: mankas82@yahoo.co.id
}

\begin{abstract}
The government's effort to reduce the number of unemployment and poverty in accordance with the Medium Term Development Plan amounted 5,1 percent is difficult to achieve if there is no effort to develop the Rill Sector. The revitalization of Rubber Plantation is based upon: (1) has a strategic role as a source of public revenue, (2) both domestic and export markets, (3) able to absorb labor, (4) ensuring environmental sustainability. The obstacles faced by the Rubber development focus on: (1) Productivity of the plantation is low, because there are many plantation which are damage by wild plant material, (2) the domestic downstream industry is less developed, (3) there is no special funding available for plantations, and (4) the policies are less supportive the development of plantation. Based on the development of rubber in 1992-1996, the result has been able to encourage economic growth and to increase the farmer's incomes in Aceh significantly.
\end{abstract}

Key word: rubber, growth, economic regional, farmer

\section{PENDAHULUAN}

Perencanaan pembangunan ekonomi suatu negara atau daerah diperlukan bermacam data statistik guna mengevaluasi hasil-hasil pembangunan yang telah dicapai pada masa lalu serta untuk membuat perencanaan dan kebijaksanaan demi tercapainya sasaran pembangunan yang telah ditentukan pada masa mendatang secara berdaya guna dan berhasil guna. Pembangunan ekonomi adalah serangkaian usaha dan kebijaksanaan yang bertujuan untuk meningkatkan taraf hidup masyarakat, memperluas kesempatan kerja, meningkatkan pertumbuhan ekonomi, pemerataan hasil-hasilnya dan mengusahakan penggeseran proses kegiatan ekonomi dari sektor primer ke arah sektor sekunder dan tertier. Upaya ini secara keseluruhan dimaksudkan untuk mengusahakan peningkatan pendapatan masyarakat secara mantap dan diikuti oleh tingkat pemerataan yang sebaik-baiknya (PDRB Aceh, 2008).

Upaya pemerintah menurunkan jumlah pengangguran dan kemiskinan sesuai dengan RPJM sebesar 5,1 persen - 8,2 persen, saat ini sulit untuk dicapai kalau tidak ada upaya yang nyata untuk mengembangkan sektor riil. Pertumbuhan sektor riil mengalami penurunan yang signifikan beberapa tahun terakhir ini. Penguatan indikator makro ekonomi seperti penguatan nilai saham dan nilai tukar rupiah tidak mencerminkan dinamika 
ekonomi masyarakat. Permasalahan kondisi sektor riil ini diakibatkan oleh lemahnya tiga sektor yang kontribusinya paling besar terhadap PDB yakni sektor Pertanian, Perdagangan dan Industri Manufaktur. Oleh karena itu perlu adanya upaya terobosan untuk mengungkit sektor ini agar tumbuh positif, dan upaya ini dapat dilakukan melalui pengembangan perkebunan, khususnya melalui pelaksanaan program revitalisasi perkebunan kelapa sawit, karet, dan kakao. Program tersebut sekaligus menindaklanjuti kebijakan pemerintah tentang revitalisasi pertanian, Perikanan dan Kehutanan (RPPK) yang dicanangkan oleh Presiden Republik Indonesia pada bulan Juni 2005 di Jatiluhur, Jawa Barat.

Program revitalisasi perkebunan adalah upaya percepatan pengembangan perkebunan rakyat melalui perluasan, peremajaan, dan rehabilitasi tanaman perkebunan yang didukung kredit investasi perbankan dan subsidi bunga oleh pemerintah dengan melibatkan perusahaan di bidang usaha perkebunan sebagai mitra pengembangan dalam pembangunan kebun, pengolahan dan pemasaran hasil (Revitalisasi perkebunan, 2007 hal 8.)

Pilihan komoditas kelapa sawit, karet, dan kakao dalam program Revitalisasi Perkebunan didasarkan beberapa pertimbangan, antara lain: (1) komoditas yang dikembangkan mempunyai peranan yang sangat strategis sebagai sumber pendapatan masyarakat, (2) komoditas yang dikembangkan mempunyai prospek pasar, baik pasar dalam negeri maupun ekspor, (3) mampu menyerap tenaga kerja baru, serta (4) mempunyai peranan dalam pelestarian fungsi lingkungan hidup.

Berdasarkan data yang ada menunjukkan bahwa pada tahun 2005 pengembangan 3 komoditas ini mampu menyerap tenaga kerja yang besar, yaitu pengembangan tanaman kelapa sawit 2,7 juta kepala keluarga (KK), pengembangan tanaman karet 1,4 juta kepala keluarga (KK) dan pengembangan tanaman kakao 500 ribu kepala keluarga (KK). Di samping itu, total ekspor komoditas perkebunan yang memberikan nilai sebesar US\$ 10,9 milyar, sekitar 70 persen berasal dari ekspor komoditas kelapa sawit, karet dan kakao. Prospek pasar ketiga komoditas tersebut sangat cerah, baik untuk pasar ekspor maupun dalam negeri. Upaya untuk mengembangkan 3 komoditas tersebut tentunya akan dapat meningkatkan peran penting komoditas tersebut dalam meningkatkan penyerapan tenaga kerja maupun penerimaan devisa ekspor.

Upaya pengembangan komoditas perkebunan dihadapkan pada berbagai kendala, antara lain: (1) produktivitas tanaman yang rendah di bawah potensi normal, karena banyak tanaman tim dan rusak dengan bahan tanaman asalan, (2) industri hilir di dalam negeri yang kurang berkembang, sehingga ekspor dalam bentuk produk primer, (3) tidak tersedia lagi pendanaan khusus untuk perkebunan, dan (4) adanya berbagai kebijakan yang kurang mendukung pembangunan perkebunan, seperti diberlakukannya berbagai pungutan yang memberatkan iklim investasi. Kendala-kendala tersebut tentunya perlu diupayakan secara terpadu melalui berbagai kegiatan yang terkait.

Pedoman pelaksanaan program revitalisasi perkebunan (karet, kelapa sawit dan kakao), merupakan acuan yang dapat digunakan dalam pelaksanaan revitalisasi perkebunan oleh pelaku usaha perkebunan dan "stakeholder" terkait lainnya. Dengan adanya pedoman ini, pengembangan perkebunan rakyat khususnya komoditas kelapa sawit, 
karet, dan kakao yang didukung dengan dana perbankan dan subsidi bunga oleh pemerintah dapat terlaksana sesuai yang diharapkan.

\section{PEMBAHASAN}

\section{Landasan Hukum}

Landasan hukum pengembangan perkebunan melalui program Revitalisasi Perkebunan adalah: (1) Peraturan Menteri Pertanian Nomor 33/Permenta JOT. 140/7/2006 tentang Pengembangan Perkebunan melalui Program Revitalisasi Perkebunan; (2) Peraturan Menteri Keuangan Nomor 117/PMK.06/2006 tentang Kredit Pengembangan Energi Nabati dan Revitalisasi Perkebunan; (3) Perjanjian Kerjasama Pendanaan antara Menteri Keuangan Dirjen Perbendaharaan dengan lima Bank Pelaksana (PT Bank Rakyat Indonesia, PT Bank Mandiri, PT BUKOPIN, PT Bank Pembangunan Daerah Sumatera Utara dan Pembangunan Daerah Sumatera Barat Bank Nagari) pada tanggal 20 Desember 2006.

\section{Tujuan Program Revitalisasi Perkebunan}

Tujuan program revitalisasi perkebunan adalah (1) Kesempatan kerja dan pendapatan masyarakat melalui pengembangan perkebunan, (2) Meningkatkan daya saing melalui peningkatan produktivitas dan pengembangan industri hilir berbasis perkebunan, (3) Meningkatkan penguasaan ekonomi nasional dengan mengikutsertakan masyarakat dan pengusaha lokal sehingga mendukung pengembangan wilayah, (4) Menganalisis pemangunan ekonomi melalui tanaman karet sejauhmana dapat meningkatkan pendapatan masyarakat secara nyata umumnya, dan pendapatan petani khususnya, (5) Mengusahakan agar peningkatan pendapatan tersebut sekaligus dapat meningkatkan pertumbuhan ekono- mi yang dapat terbagi atau diterima masyarakat seadil-adilnya.

\section{Peranan Tanaman Karet}

Selama ini, Indonesia bersama 2 negara produsen karet alam terbesar dunia yaitu Thailand dan Malaysia, memberikan kontribusi sebesar 75 persen terhadap total produksi karet alam dunia. Khususnya Indonesia memberikan kontribusi sebesar 26 persen dan total produksi karet alam dunia. Berdasarkan data dan kecenderungan membaiknya harga karet alam pada beberapa tahun terakhir, diproyeksikan hingga tahun 2020 konsumsi karet alam dunia akan cenderung mengalami peningkatan rata-rata sebesar 2,6 persen per tahun. Hal ini sejalan dengan meningkatnya pendapatan, perekonomian negara berkembang khususnya pada negara-negara dengan populasi penduduk yang besar seperti India dan China.

China dan negara-negara yang industrinya sedang berkembang membutuhkan karet alam untuk mendukung pengembangan industri tersebut. Pada tahun 1999, China membutuhkan karet alam sebesar 852 ribu ton dan pada tahun 2004 meningkat menjadi sebesar 1.630 ribu ton atau equivalen dengan peningkatan sebesar 91 persen. Meningkatnya kebutuhan karet: alam China dalam upaya mendukung peningkatan yang sangat pesat di bidang perindustrian sebagai implikasi dari pertumbuhan ekonomi sebesar 7 persen setiap tahun. Diperkirakan sampai dengan tahun 2010 kebutuhan karet alam China akan meningkat sebesar 7 persen setiap tahunnya. Memperjelas peranan Indonesia dalam kaitannya dengan ekspor karet selama enam tahun terakhir dapat dilihat pada Tabel 1 .

Tabel 1 menjelaskan peranan karet dalam menumbuhkan ekonomi secara nasional 
Rekomendasi yang diberikan penulis adalah sebagai berikut: (a) Diperlukan pembangunan perkebunan karet di Aceh baik perkebunan rakyat maupun perkebunan besar; diperlukan kebijakan melalui tone from the top, (b) dengan mengadopsi pola ADB yang sudah pernah berhasil di Aceh, sistem pembiayaan dengan supervisor kredit, lahan tidak fiktif, petani tidak fiktif, dan bantuan tidak fiktif.

\section{DAFTAR PUSTAKA}

Arsyad, Lincolin, 2001, Pengantar Perencanaan dan Pembangunan Ekonomi Daerah, Yogyakarta: Universitas Gadjah Mada.

Bappeda Aceh dan BPS 2003, Produk Domestik Regional Bruto Provinsi Aceh (menurut lapangan usaha), Banda Aceh: Kerjasama BAPPEDA Dan Badan Pusat Statistik Provinsi Aceh.

Blakkely, E. J, 2001, Planning Local Economic Development Theory and Practice, Sage Publications, University of California.

BPS, 2002, Statististik Karet Indonesia, Katalog BPS 5504002, Jakarta: Badan Pusat Statistik.
BPS, 2007, Statistik Karet Indonesia, Kata$\log$ BPS 5504002, Jakarta: Badan Pusat Statistik.

Cray, C. dkk, 2002. Pengantar Evaluasi Proyek, Edisi Kedua, Jakarta: PT Gramedia Pustaka Utama.

Departemen Pertanian, 2007, Pedoman Umum Program Revitalisasi Perkebunan, Jakarta: Direktorat Jenderal Perkebunan, Departemen Pertanian.

Michael P. Todaro, 2000, Pembangunan Ekonomi di Dunia Ketiga Edisi Ketujuh, Jilid 1, Alih Bahasa: Drs. Haris Munandar, M., A.New York University, Amerika Serikat.

Tarigan, R., 2003, Perencanaan Pembangunan Wilayah Edisi Revisi, Jakarta: PT Bumi Aksara.

TCSSP, 2001, Laporan Tahunan Proyek TCSSP Provinsi Aceh, Banda Aceh.

Tomek, W.G dan Robinson, K. L., 1981, Agricultural Product Prices, Secound Edition, Ithaca and London: Cornel University Press. 


\title{
PEDOMAN PENULISAN \\ JURNAL EKONOMI PEMBANGUNAN FAKULTAS EKONOMI UNIVERSITAS MUHAMMADIYAH SURAKARTA
}

Terbit: 2 kali dalam setahun pada bulan Juni dan Desember

\author{
Akreditasi Jurnal: \\ KEPUTUSAN DIREKTUR JENDERAL PENDIDIKAN TINGGI \\ KEMENTERIAN PENDIDIKAN NASIONAL NOMOR: 51/DIKTI/Kep./2010 \\ (masa berlaku Juni 2010 s.d Juni 2013)
}

1. Artikel ditulis dengan bahasa Indonesia atau bahasa Inggris dalam bidang kajian masalah ekonomi dan pembangunan.

2. Substansi artikel diharapkan sejalan dengan Panduan Akreditasi Berkala Ilmiah 2006, yang diterbitkan Direktorat Penelitian dan Pengabdian kepada Masyarakat (DP2M) Direktorat Jenderal Pendidikan Tinggi Republik Indonesia).

3. Artikel ditulis dengan kaidah tata bahasa Inggris ataupun bahasa Indonesia yang baik dan benar.

4. Sistematika Penulisan

Sistematika penjenjangan atau peringkat judul artikel dan bagian-bagiannya dilakukan dengan cara berikut:

(1) Judul ditulis dengan huruf besar semua, di bagian tengah atas pada halaman pertama

(2) Sub Bab Peringkat 1 ditulis dengan huruf pertama besar semua di tengah/center

(3) Sub Bab Peringkat 2 ditulis dengan huruf besar-kecil rata tepi kiri

- Sistematika artikel hasil penelitian adalah: judul; nama penulis (tanpa gelar akademik); nama dan alamat institusi, alamat e-mail penulis, abstrak (maksimum 150 kata) yang berisi tujuan, metode, dan hasil penelitian; kata kunci (4-5 kata kunci); pendahuluan (tanpa ada subjudul) yang berisi latar belakang, sedikit tinjauan pustaka, dan tujuan penelitian; metode; hasil penelitian dan pembahasan; kesimpulan; daftar rujukan (hanya memuat sumber-sumber yang dirujuk).

\section{JUDUL UTAMA:}

\section{Sub Judul}

Penulis $1^{1}$ dan Penulis $2^{2}$

${ }^{1}$ Nama instansi/lembaga Penulis 1

Alamat lengkap instansi penulis, nomor telepon instansi penulis

${ }^{2}$ Nama instansi/lembaga Penulis 2

Alamat lengkap instansi penulis, nomor telepon instansi penulis

(jika nama instansi penulis 1 dan 2 sama, cukup ditulis satu saja)

E-mail penulis 1 dan 2:

Abstrak: Abstrak dalam bahasa Indonesia (125 - 150 kata)

Kata kunci: 4 - 5 katal frase

Abstract: Abstract in english (125 - 150 words)

Keywords: $4-5$ words/ phrase

\section{PENDAHULUAN}

(berisi latar belakang, sekilas tinjauan pustaka, dan tujuan penelitian, yang dimasukkan dalam paragraf paragraf bukan dalam bentuk subbab)

METODE PENELITIAN

Subbab

Subbab

...

\section{HASIL ANALISIS DAN PEMBAHASAN}

Pedoman Penulisan Jurnal Ekonomi Pembangunan FE Universitas Muhammadiyah Surakarta 


\title{
Subbab
}

\section{KESIMPULAN \\ DAFTAR PUSTAKA}

- Sistematika artikel hasil pemikiran adalah: judul; nama penulis (tanpa gelar akademik); nama dan alamat institusi, alamat e-mail penulis, abstrak (maksimum 150 kata); kata-kata kunci (4-5 kata kunci); pendahuluan (tanpa ada subjudul) yang berisi latar belakang dan tujuan atau ruang lingkup tulisan; bahasan utama (dapat dibagi ke dalam beberapa sub-judul); penutup atau kesimpulan; daftar rujukan (hanya memuat sumber-sumber yang dirujuk).

\section{JUDUL UTAMA: \\ Sub Judul}

Penulis $1^{1}$ dan Penulis $2^{2}$

${ }^{1}$ Nama instansi/lembaga Penulis 1

Alamat lengkap instansi penulis, nomor telepon instansi penulis

${ }^{2}$ Nama instansi/lembaga Penulis 2

Alamat lengkap instansi penulis, nomor telepon instansi penulis

(jika nama instansi penulis 1 dan 2 sama, cukup ditulis satu saja)

E-mail penulis 1 dan 2 :

\author{
Abstrak: Abstrak dalam bahasa Indonesia (125--150 kata) \\ Kata kunci: 4 - 5 katal frase \\ Abstract: Abstract in english (125 - 150 words) \\ Keywords: $4-5$ words/ phrase

\section{PENDAHULUAN PEMBAHASAN \\ KESIMPULAN} \\ DAFTAR PUSTAKA
}

5. Artikel diketik pada kertas kwarto berkualitas baik. Dibuat sesingkat mungkin sesuai dengan subyek dan metode penelitian (bila naskah tersebut ringkasan penelitian), biasanya 20-25 halaman dengan spasi satu, untuk kutipan paragraf langsung diindent (tidak termasuk daftar pustaka).

6. Marjin atas, bawah, dan samping harus dibuat paling tidak satu inci.

7. Abstrak, ditulis satu paragraf sebelum isi naskah. Abstrak dalam dua bahasa yaitu bahasa Indonesia dan bahasa Inggris. Abstrak tidak memuat uraian matematis, dan mencakup esensi utuh penelitian, metode dan pentingnya temuan dan saran atau kontribusi penelitian.

8. $\quad$ a. Penulisan numbering diintegrasikan dalam paragraf, contohnya:

Tujuan dilakukannya penelitian ini adalah: (1) Untuk mengetahui apakah CSR berpengaruh positif terhadap nilai perusahaan, (2) Untuk mengetahui apakah persentase kepemilikan manajemen berperan sebagai variabel moderating dalam hubungan antara CSR dengan nilai perusahaan, dan (3) Untuk mengetahui apakah tipe industri berperan sebagai variabel moderating dalam hubungan antara CSR dengan nilai perusahaan?

b. Penulisan bullet juga diintegrasikan dalam paragraf dengan menggunakan tanda koma pada antarkata/kalimat tanpa bullet.

9. Tabel dan gambar, untuk tabel dan gambar (grafik) sebagai lampiran dicantumkan pada halaman sesudah teks. Sedangkan tabel atau gambar baik di dalam naskah maupun bukan harus diberi nomor urut.

- Tabel atau gambar harus disertai judul. Judul tabel diletakkan di atas tabel sedangkan judul gambar diletakkan di bawah gambar.

Pedoman Penulisan Jurnal Ekonomi Pembangunan FE Universitas Muhammadiyah Surakarta 
- Sumber acuan tabel atau gambar dicantumkan di bawah tabel atau gambar.

- Garis tabel yang dimunculkan hanya pada bagian header dan garis bagian paling bawah tabel sedangkan untuk garis-garis vertikal pemisah kolom tidak dimunculkan.

Contoh: Tabel

Tabel 1. Bentuk-bentuk Mobilitas Penduduk

\begin{tabular}{llll}
\hline No & Bentuk Mobilitas & Batas Wilayah & Batas Waktu \\
\hline 1. & Ulang-alik (commuting) & Dukuh (dusun) & 6 jam atau lebih dan kembali pada hari yang sama \\
2. & Menginap/mondok di daerah tujuan & Dukuh (dusun) & Lebih dari satu hari tetapi kurang dari 6 bulan \\
3. & Permanen/menetap di daerah tujuan & Dukuh (dusun) & 6 bulan atau lebih menetap di daerah tujuan \\
\hline
\end{tabular}

Sumber: Ida Bagoes, 2000

\section{Contoh: Gambar}

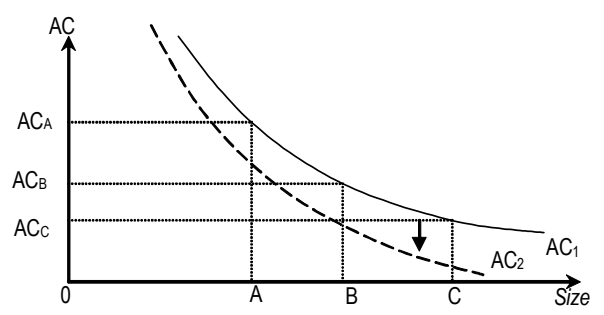

Sumber: Saunders (1997: 291)

Gambar 2. Dampak Peningkatan Teknologi

10. Cara penulisan rumus, Persamaan-persamaan yang digunakan disusun pada baris terpisah dan diberi nomor secara berurutan dalam parentheses (justify) dan diletakkan pada margin kanan sejajar dengan baris tersebut. Contoh:

$\mathrm{wt}=\mathrm{f}\left(\mathrm{y}_{\mathrm{t}}, \mathrm{k}_{\mathrm{t}}, \mathrm{w}_{\mathrm{t}-1}\right)$

11. Keterangan Rumus ditulis dalam satu paragraf tanpa menggunakan simbol sama dengan (=), masingmasing keterangan notasi rumus dipisahkan dengan koma. Contoh:

Dimana $\mathbf{w}$ adalah upah nominal, $\mathbf{y t}$ adalah produktivitas pekerja, kt adalah intensitas modal, $\mathbf{w}_{\mathbf{t}-\mathbf{1}}$ adalah tingkat upah periode sebelumnya.

12. Perujukan sumber acuan di dalam teks dengan menggunakan nama akhir dan tahun. Kemudian bila merujuk pada halaman tertentu, penyebutan halaman setelah penyebutan tahun dengan dipisah titik dua. Untuk karya terjemahan dilakukan dengan cara menyebutkan nama pengarang aslinya.

Contoh:

- Yuni (2008: 23) memandang bahwa .....

- Fatimah dan Daryono (1997) menunjukkan adanya ....

- Didit dkk (2007) berkesimpulan bahwa....

- Untuk meningkatkan perekonomi daerah .... (Yuni, Triyono, dan Agung Riyardi, 2009).

- Maya (2009) berpendapat bahwa ....

13. Setiap kutipan, baik langsung maupun tidak langsung, harus diikuti sumbernya (lihat poin no. 10) dan dicantumkan juga dalam daftar pustaka. Contoh:

Di dalam paragraf isi tercantum kutipan dari: Buiter (2007:15) berpendapat bahwa...

Maka dalam daftar pustaka harus ada sumber referensinya seperti berikut:

Buiter, W. H., (2002). The Fiscal Theory of the Price Level: A Critique, Economic Journal, 112(127): 459-480.

Pedoman Penulisan Jurnal Ekonomi Pembangunan FE Universitas Muhammadiyah Surakarta 
14. Sedapat mungkin pustaka-pustaka yang dijadikan rujukan adalah pustaka yang diterbitkan 10 tahun terakhir dan diutamakan dari jurnal ilmiah.

15. Unsur yang ditulis dalam daftar pustaka secara berturut-turut meliputi: (1) nama akhir pengarang, nama awal, nama tengah, tanpa gelar akademik, (2) tahun penerbitan, (3) judul termasuk subjudul, (4) tempat penerbitan, (5) nama penerbit.

Contoh cara penulisan:

a. Format rujukan dari buku: Nama pengarang, (tahun), Judul Buku, edisi, Kota penerbit, Nama penerbit. Jika penulis sebagai editor tunggal, ditulis (Ed.) di belakang namanya. Ditulis (Eds.) jika editornya lebih dari satu orang. Kemudian bila pengarang lebih dari tiga orang, dituliskan nama pengarang pertama dan yang lain disingkat 'dkk' (pengarang domestik) atau 'et.al.' (pengarang asing).

Enders, W., (2004), Applied Econometric Time Series, Second edition, New York: John Wiley \& Sony Inc. Purnomo, Didit (Ed.). (2005). The Role of Macroeconomic Factors in Growth. Surakarta: Penerbit Muhamadiyah University Press.

b. Format rujukan dari artikel dalam buku ditulis: Nama editor (Ed.), (tahun), Judul tulisan/karangan. Judul buku, hlm atau pp., kota penerbit: nama penerbit

Daryono (Ed.). (2005). Concept of Fiscal Decentralization and Worldwide Overview (hlm. 12-25). Surakarta: Penerbit Muhammadiyah University Press.

c. Format rujukan dari artikel dalam jurnal/majalah/koran: Nama pengarang (tahun). judul tulisan/ karangan. Nama jurnal/majalah/koran, hlm atau pp., volume (nomor), halaman. Jika rujukan koran tanpa penulis, nama koran ditulis diawal.

Rodden, J., (2002). The dilemma of Fiscal Federalism: Grants and Fiscal Performance arround the World. American Journal of Political Science, 46 (3): 670-687.

Triyono (2008). Perimbangan Keuangan Pusat dan Daerah Sebagai Pelaksanaan Desentralisasi Fiskal Efek. Warta Ekonomi, Vol. 4, Agustus: 46-48.

Haryanto, S., (2007, 13 November). Desentralisasi Fiskal dan Pembangunan Ekonomi. Harian Jakarta, hlm.4.

Harian Jogjakarta, (2007, 1 April). Hubungan Keuangan Pusat-Daerah di Indonesia. hlm. 4.

d. Format rujukan dari internet, tanggal akses dicantumkan.

Setyowati, E.,. Keuangan Publik dan Sistem Harga. http://www.ekonomipublik.com/akt/pdf/akt452.pdf.

Diakses tanggal 27 Mei 2009.

\section{Pengiriman Artikel}

1. Artikel dikirimkan sebanyak 2 eksemplar hardcopy, dan softcopy berupa file. File bisa dikirim melalui email jepums@yahoo.co.id atau dalam media cd.

2. Artikel yang dikirim wajib dilampiri biodata ringkas pendidikan termasuk catatan riwayat karya-karya ilmiah sebelumnya yang pernah dipublikasikan, insitusi dan alamatnya, nomor telpon kontak atau e-mail penulis.

3. Penulis yang menyerahkan artikelnya kepada editor atau penerbit, harus menjamin bahwa naskah yang diajukan tidak melanggar hak cipta, belum dipublikasikan atau telah diterima untuk dipublikasi oleh jurnal lainnya.

4. Kepastian pemuatan atau penolakan naskah akan diberitahukan secara tertulis. Penulis yang artikelnya dimuat mendapatkan jurnal tersebut. Artikel yang tidak dimuat tidak akan dikembalikan.

\section{Alamat Redaksi Jurnal Ekonomi Pembangunan Fakultas Ekonomi Universitas Muhammadiyah Surakarta: \\ Redaksi Jurnal Ekonomi Pembangunan Fakultas Ekonomi Universitas Muhammadiyah Surakarta Jalan A. Yani Tromol Pos I Pabelan SURAKARTA 57102 Telp. 0271-717417 psw 229}

Pedoman Penulisan Jurnal Ekonomi Pembangunan FE Universitas Muhammadiyah Surakarta 
TENTANG JURNAL:

\title{
JURNAL EKONOMI PEMBANGUNAN
}

Kajian Masalah Ekonomi dan Pembangunan

ISSN 1411- 6081

\author{
Pimpinan Redaksi \\ Didit Purnomo
}

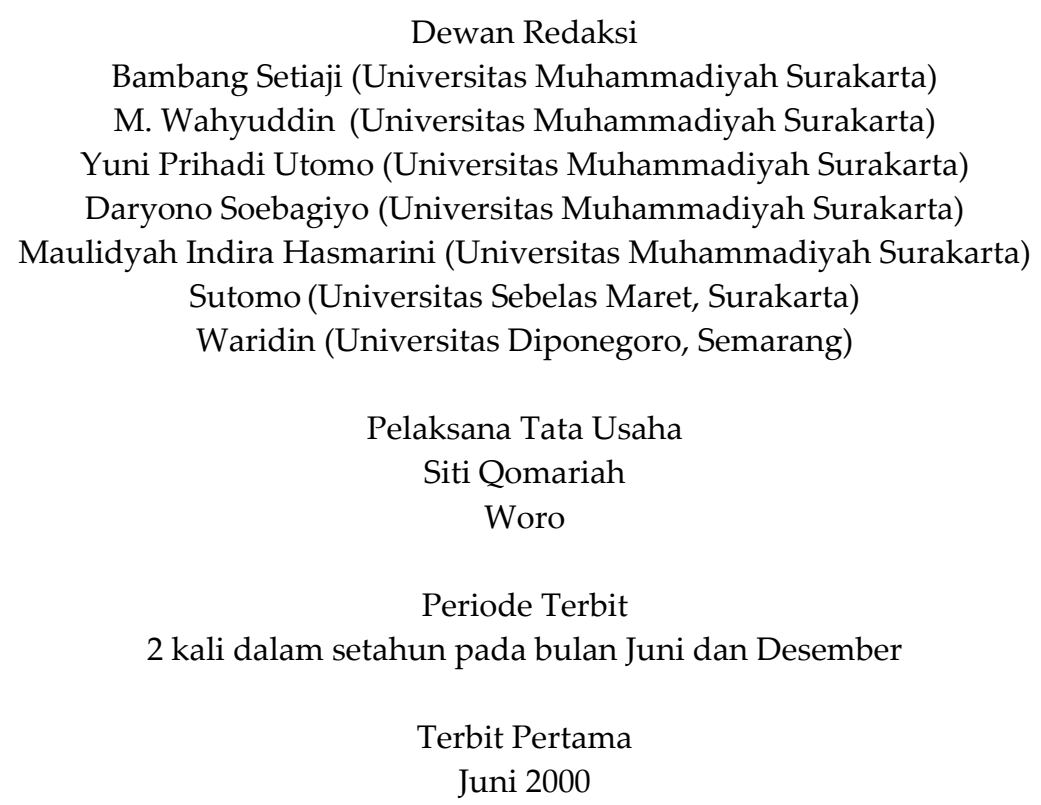

Jurnal EKONOMI PEMBANGUNAN merupakan jurnal ilmiah yang berisikan hasil penelitian dan kajian teoritis mengenai masalah-masalah ekonomi dan pembangunan, khususnya di Indonesia. Diterbitkan oleh Balai Penelitian dan Pengembangan Ekonomi Fakultas Ekonomi Universitas Muhammadiyah Surakarta.

Redaksi menerima sumbangan tulisan yang belum pernah diterbitkan atau dalam proses terbit oleh media lain. Naskah diketik di atas kertas HVS kuarto spasi satu sepanjang lebih kurang 20-25 halaman, dengan format seperti tercantum pada prasyarat naskah jurnal EKONOMI PEMBANGUNAN di halaman belakang. Naskah yang masuk akan dievaluasi dan disunting untuk keseragaman format dan tata cara lainnya.

Alamat Penyunting dan Tata Usaha: Subag Tata Usaha Fakultas Ekonomi Universitas Muhammadiyah Surakarta, Jl. A. Yani, Tromol Pos 1, Pabelan, Surakarta 57102; Telpon (0271) 717417 psw 229,

E-mail: jepums@yahoo.co.id

Website: http://www.ums.ac.id atau http://www.paradejurnal.wordpress.com

Simak informasi jurnal: http://www.paradejurnal.wordpress.com

Admin: Mirat Sidharta. SE

Pedoman Penulisan Jurnal Ekonomi Pembangunan FE Universitas Muhammadiyah Surakarta 